\title{
Private companies' change management under innovation-driven Thailand 4.0 context in the Bangkok Area
}

\author{
Kawinphat Lertpongmane ${ }^{1,{ }^{*}}$ \\ ${ }^{1}$ Suan Sunandha Rajabhat University, Bangkok, Thailand
}

\begin{abstract}
The purposes of this research were; (1) to study the factors affecting the change management of private companies in the Bangkok area under the context of Thailand 4.0 driven by innovation and (2) to propose a development guideline for the change management of private companies in the Bangkok area under the context of Thailand 4.0 driven by innovation. The sample population in this study was 400 private company employees and 4 private company executives in the Bangkok area. This is a hybrid research study which combined qualitative and quantitative research methods, including interviews with private company executives, research for data from technical documents, and the use of a questionnaire as a quantitative instrument. The statistics for data analysis included Percentage, Mean, Standard Deviation, T-test, One-way ANOVA, and Multiple Regression.
\end{abstract}

\section{Introduction}

Leaders are individuals with an important role in the management who ensure that organizations and their operations can carry out the set objectives and goals. An organization's leader is a person who sets the directions of management and operations according to the objectives and goals of the organization. They are the core of management who can accomplish tasks through the cooperation of others. A good leader's duty is to coordinate and lead the organization to their goals.

They must have individuals with broad vision who can gain others' acceptance and are willing to both lead and follow. Successful leaders must have "leadership" and to lead an organization, a leader must have a variety of knowledge and abilities as well as being up-todate with changing situations. They must keep up with news and knowledge in various fields and adapt them in their department or organization.

This knowledge is required so they can take the commanding role in the organization and can assist personnel who do not have adequate understanding of any area at any time. An organization in which its executives are leaders with knowledge, competence, expertise, morality, and ethics, is an organization with a competitive advantage that will lead to the achieving of the targets set [1].

\footnotetext{
${ }^{*}$ Corresponding author: kawinphat.le@ssru.ac.th
} 
Executives are an important factor, especially in Thai society. Executives with good leadership are those who are compassionate and operate with clarity on a basis of reason and integrity. They are thinkers and analysts with creativity who can analyze various situation efficiently and use their far-sighted perspectives to predict future possibilities based on their past experience. They are individuals with an ability to think critically and make good management decisions. They have knowledge, up-to-date information, and understanding of different roles and duties.

They can make decisions and they have appropriate skills and approaches conducive to making righteous and timely decisions. They also have good interpersonal relationships with their superiors, subordinates, colleagues, and other people. Leaders who have all these basic qualities will enable subordinates to perform with diligence, unity, determination, willingness, and morale which in turn will affect the success of the organization.

Over the past two decades, there have been various studies to find leadership appropriate to the present era of change. One of the well-known new theoretical concepts that is highly recognized nowadays is Transformational Leadership - a new theory of leadership where leaders are motivated to hold high morality, decentralize their power, create mutual visions, and motivate their followers to have leadership.

Transformational Leadership considers the characteristics of leaders, behavior, power, as well as the relevant situational variables which provide a wider concept than other leadership theories. [2] suggested a dynamic between 2 types of leadership with different relationships between leaders and followers - Transformational and Transactional leadership. When used together, it results in management with continuity and continued capabilities to transform, improve, or adjust accordingly to the increasing demand of the followers.

For Transactional Leadership, leaders require their followers to follow their commands in exchange of rewards which is a basic level of need satisfaction in Maslow's Hierarchy of Needs. On the contrary, Transformational Leadership can lead to the change of the organization effectively. Thus, for an organization to be successful as a whole, it also depends on the responsibility and knowledge in various situations of quality leaders, who must have an understanding of their roles and organization structure and lead the organization to be accepted by the society [3]. The leaders should also be open to learning of new things and courageous enough to put them to good use in practice [4]

Thailand 4.0 is a policy vision of Thailand's economic development and is the government's economic development model to adjust, organize, direct, and create ways to develop the country to prosper under new opportunities and threats that change quickly and drastically in the 21 st century.

Among the rapid and drastic changes is the disruption of Cloud Computing which has arisen in response to the demand of companies which do not want to have a data center of their own. This innovation allows companies to access various services on the Cloud including data storage or even applications.

This emergence affects companies in the data center business include those specialized in hardware, database, and software, resulting in their operating problems. Therefore, executives or entrepreneurs of private sectors must be able to adapt amidst the changes that occur in order to lead their organizations and businesses through these hardships. In this research, the study of change management was done on private companies in the Bangkok area for the benefit of organizations and businesses, as well as the general public.

\section{Research objectives}

1. To study the factors affecting the change management of private companies in the Bangkok area under the context of Thailand 4.0 driven by innovation. 
2. To propose a development guideline for the change management of private companies in the Bangkok area under the context of Thailand 4.0 driven by innovation.

\section{Methodology}

The research is a mixed-method study, which combined qualitative research and quantitative research approaches.

\subsection{Research method}

Qualitative research - included of 2 sections: 1) Interviews with 4 private company executives in Bangkok - to study change management of private companies under the context of Thailand 4.0 driven by innovation in the Bangkok area. 2) Research on related documents.

Quantitative research - a questionnaire, which was created by the research team based on related concepts, theories, and previous studies, was used as data collection instrument and divided into 2 parts:

Part 1: 6 multiple choice questions enquiring the respondents' demographic information, including gender, age, educational level, marital status, average monthly income, and work position.

Part 2: 15 questions concerning 3 areas of factors affecting the change management of private companies under the context of Thailand 4.0 driven by innovation in the Bangkok area.

\subsection{Population and Sampling}

\section{Qualitative research}

Interviews were conducted with 4 executives from 4 private companies in Bangkok namely:

1) Oishi Group Public Company Limited

2) Prince Palace Hotel

3) Global (Sam 1996) Security Guard Company Limited

4) Belton Industrial (Thailand) Company Limited

Quantitative research

The population used in this research was employees of private companies in Bangkok.

The sample population was 400 employees of private companies in Bangkok who were selected using Purposive Sampling and Convenience Sampling.

Sampling method

Sample population in this research was selected using Purposive Sampling and

Convenience sampling from private company employees in Bangkok area until 400 samples were achieved.

\subsection{Research tool development}

\section{Qualitative Research}

1) Interview form with 4 private company executives in Bangkok - to study change management of private companies under the context of Thailand context 4.0 driven by innovation in the Bangkok area.

2) Data collected from research on academic studies and related documents.

Quantitative Research 
The research instrument used was a questionnaire created by the research team based on related concepts, theories, and previous studies, and was used as data collection instrument and divided into 2 parts:

Part 1: 6 multiple choice questions inquiring the respondents' demographic information, including gender, age, educational level, marital status, average monthly income, and work position.

Part 2: 15 questions on factors affecting the change management of private companies under the context of Thailand 4.0 driven by innovation in the Bangkok area. The questions concerned 3 areas;

1. INPUT $=$ Transformational Leadership

2. PROCESS $=$ Change management under the context of Thailand 4.0 driven by innovation

3. OUTPUT $=$ Work performance of company employees

\subsection{Data collection}

\section{Qualitative research}

Data collection was conducted as follows;

1.1 Documentary research - data from documents used in this research could be divided into 2 types:

A. Primary Data - refers to raw data that has not been analyzed including data retrieved directly from sources through participatory observation and interviews with 4 private company executives in Bangkok.

B. Secondary Data - refers to data from documents that have been analyzed in various forms, including research and collection of data from pre-compiled sources before applying the data to achieve the study's objectives.

1.2 Interviews - the interviews used in this study included Semi-structured or Guided Interview, in which an interview guide was used as a tool in various formats, and In-depth Interview, or intensive individual interview, which was used with the study's key informants.

\section{Quantitative research}

Data collection was conducted using questionnaires created by the researcher on samples selected through purposive sampling and convenience sampling among private company employees in Bangkok. When all the questionnaire forms were returned, they were then checked for accuracy and completeness before being processed in the data analysis.

\subsection{Data Analysis}

\section{Qualitative research}

Qualitative research (interviews) was focused on narration and Direct Observation. The data collected from the well-selected informants were analyzed to help supplement the research as the clear and solid answers were used for Content Analysis.

Quantitative research

The change management of private companies in the Bangkok area under the context of Thailand 4.0 driven by innovation was analyzed and explained by using statistics as follows:

1. Descriptive statistics - including Frequency, Percentage, Mean, and Standard deviation.

2. Inferential statistics - including T-test, One-way ANOVA, and Multiple Regression. 


\section{Result}

\subsection{Demographic information of respondents}

General information of respondents who were 400 private company employees in Bangkok could be classified by gender, age, education level, marital status, income per month, and work position as follows;

The majority of the respondents, $61.8 \%$ or 247 individuals, were female, while 153 males contributed to $38.3 \%$ of all respondents. Most of them, $47.0 \%$ or 188 individuals, aged between 30-39 years. 312 respondents or $78.0 \%$ had lower than bachelor degree education. $55.0 \%$ or them or 220 individuals were single, while 156 respondents or $39.0 \%$ had a monthly income of 20,001-30,000 THB. Most respondents, $64.0 \%$ or 256 individuals, worked in a general employee position.

\subsection{Factors affecting the change management of private companies under the context of Thailand 4.0 driven by innovation in the Bangkok area}

Table 1. Mean and Standard Deviation of the "INPUT" of change management of private companies in Bangkok under the context of Thailand Context 4.0 driven by innovation.

\begin{tabular}{|l|c|c|c|}
\hline \multicolumn{1}{|c|}{ INPUT } & $\overline{\mathbf{X}}$ & S.D. & Interpretation \\
\hline Executives are the driving power of employees in the company. & 3.82 & 0.76 & High \\
\hline Executives create unity value for employees. & 3.62 & 0.86 & High \\
\hline Executives are a good role model in their work. & 3.57 & 0.90 & High \\
\hline $\begin{array}{l}\text { Executives can organize the management system to allocate } \\
\text { duties and responsibilities appropriate to the knowledge and } \\
\text { capability of the organization. }\end{array}$ & 3.71 & 0.83 & High \\
\hline $\begin{array}{l}\text { Executives can analyze internal and external factors and use } \\
\text { them to create strategic plans. }\end{array}$ & 3.91 & 0.71 & High \\
\hline Total & 3.73 & 0.81 & High \\
\hline
\end{tabular}

From Table 1, it was found that respondents' opinion on the "INPUT" of change management of private companies in Bangkok under the context of Thailand 4.0 driven by innovation was overall at a high level with mean at 3.73. When considered item by item, the mean scores of all factors were at a high level. "Executives can analyze internal and external factors and use them to create strategic plans." was given highest mean score at 3.91, followed by "Executives are the driving power of employees in the company." at 3.81, and "Executives can organize the management system to allocate duties and responsibilities appropriate to the knowledge and capability of the organization." at 3.71.

Table 2. Mean and Standard Deviation of the "PROCESS" of change management of private companies in Bangkok under the context of Thailand 4.0 driven by innovation.

\begin{tabular}{|l|c|c|c|}
\hline \multicolumn{1}{|c|}{ PROCESS } & $\overline{\mathbf{X}}$ & S.D. & Interpretation \\
\hline Executives operate with flexibility in management. & 3.49 & 0.90 & High \\
\hline $\begin{array}{l}\text { Executives treat all subordinates with good ethics and } \\
\text { morality. }\end{array}$ & 3.43 & 0.84 & High \\
\hline $\begin{array}{l}\text { Executives can assign work plans that are consistent with } \\
\text { the external changing conditions. }\end{array}$ & 3.41 & 0.88 & High \\
\hline $\begin{array}{l}\text { Executives have strategies for motivating and } \\
\text { incentivizing subordinates in their work. }\end{array}$ & 3.75 & 0.69 & High \\
\hline $\begin{array}{l}\text { Executives can make timely decisions to modify plans } \\
\text { and management to be in accordance with changes. }\end{array}$ & 3.64 & 0.74 & High \\
\hline Total & 3.54 & 0.81 & High \\
\hline
\end{tabular}


From Table 2, it was found that respondents' opinion on the "PROCESS" of change management of private companies in Bangkok under the context of Thailand 4.0 driven by innovation was overall at a high level with mean at 3.54. When considered item by item, the mean scores of all factors were at a high level. "Executives have strategies for motivating and incentivizing subordinates in their work." was given highest mean score at 3.75, followed by "Executives can make timely decisions to modify plans and management to be in accordance with changes." at 3.64, and "Executives operate with flexibility in management." at 3.49 .

Table 3. Mean and Standard Deviation of the "OUTPUT" of change management of private companies in Bangkok under the context of Thailand 4.0 driven by innovation.

\begin{tabular}{|l|c|c|c|}
\hline \multicolumn{1}{|c|}{ OUTPUT } & $\overline{\mathbf{X}}$ & S.D. & Interpretation \\
\hline Possibility of growth in the company. & 3.75 & 0.81 & High \\
\hline Level of work and life balance. & 3.60 & 0.79 & High \\
\hline $\begin{array}{l}\text { Ability to perform tasks in its entirety } \\
\text { and without error. }\end{array}$ & 3.76 & 0.62 & High \\
\hline Ability to manage work in time. & 3.71 & 0.59 & High \\
\hline Performance of employees in the company. & 3.64 & 0.60 & High \\
\hline Total & 3.69 & 0.68 & High \\
\hline
\end{tabular}

From Table 3, it was found that respondents' opinion on the "OUTCOME" of change management of private companies in Bangkok under the context of Thailand 4.0 driven by innovation was overall at a high level with mean at 3.69. When considered item by item, the mean scores of all factors were at a high level. "Ability to perform tasks in its entirety and without error." was given highest mean score at 3.76 , followed by "Possibility of growth in the company." at 3.75, and "Ability to manage work in time." at 3.71.

\subsection{Qualitative analysis results}

The results on the change management and the proposal of a development guideline for the change management of private companies in the Bangkok area under the context of Thailand 4.0 driven by innovation are summarized as follows;

Part 1: The change management of private companies in the Bangkok area under the context of Thailand 4.0 driven by innovation.

1. Opinions about the current situation of "Thailand 4.0 driven by innovation" Executives viewed it as a new change which several private companies, whether they are in products and services, tourism, or technology industries, have to face. They viewed that this change in technology will provide convenience in the companies' operation, resulting in satisfaction for more customers yet in a shorter time when compared with traditional corporate management.

2. Opinions on whether "Thailand 4.0 driven by innovation" positively or negatively affects their company - Executives viewed that it has positive effects on their organizations as it makes work become more efficient, puts more emphasis on decentralization of decision-making, and changes the operation process which results in timely reduction of possible mistakes. Technology is used to help manage the work as a system, reduce the size of the organization, and reduce the number of employees leading to more efficient employees being at work, as well as immediate responses to customer needs.

3. The present "Thailand 4.0 driven by innovation" results in every company having to accept the change by focusing on creating their own products with an application of technology to help expand production capacity and to operate with efficient management. This is to help the companies to survive by responding to the needs of their customers as quickly as possible in order to gain a share in their industry's market. 
4. When asked how well their company copes with the context of "Thailand 4.0 driven by innovation" and how they themselves cope with the current situation, the executives stated that all companies must accept the current changes. Every company has to adapt to the use of technology and adjust accordingly to the needs of customers which are constantly changing. Therefore, the management has to be adjusted all the time, not sticking to the old forms of management and use automation to increase customer satisfaction and the number of products and services.

5. As for the change management under the context of "Thailand 4.0 driven by innovation", it was found that the companies expand their production capacity by using technology to assist in their management. They were also quick to adapt to the changing needs of their customers. The present day is an age of transforming management, thus there is a combination of traditional approach and new approach which engages the use of technology to help manage the entire system. Therefore, the management has to adapt in order to change the method of operation to be more compatible with the future increasing use of automation.

Part 2: Development guideline for the change management of private companies in the Bangkok area under the context of Thailand 4.0 driven by innovation

Most private companies need to create new innovation for their clients by developing their products to be more up-to-date in response to current customer behavior. In addition, the management should also encourage their employees to gain more knowledge and use their knowledge in technology for better performance. Furthermore, technology should be used to assist management of the human workforce. This will allow executives online supervision of the operations and if there are errors in the processes, executives can then make timely adjustments to the operations. Therefore, for a business to survive in this era of drastic change, they need to adapt and develop their potential for the better.

\section{Discussion}

The study results revealed the demographic information of the respondents, employees of private companies in the Bangkok area, that most of them were female, single, aged 30-39, had an education level lower than a bachelor's degree, received monthly income of 20,001$30,000 \mathrm{THB}$, and held a general employee position. The is consistent with a study [5] "Selfdevelopment needs of staff at a beverage production company in Amata Nakhon Industrial Estate, Chonburi Province" and [6]. "Organization change management for accommodating Chinese Travellers: A case study of 4 stars hotels, Tambon Chang Klan, Chiang Mai Province".

The change management of private companies in the Bangkok area under the context of Thailand 4.0 driven by innovation can be discussed based on individual areas as follows;

1. The "INPUT" of change management of private companies in Bangkok under the context of Thailand 4.0 driven by innovation was overall at a high level with factors such as; executives are able to analyze internal and external factors and use them to create strategic plans, executives are the driving power of employees in the company, and executives are able to organize the management system to allocate duties and responsibilities appropriate to the knowledge and capability of the organization. This is in line with the study of [6]. "Organization change management for accommodating Chinese Travellers: A case study of 4 stars hotels, Tambon Chang Klan, Chiang Mai Province" which found that hotel executives had plans for change management of the hotels at a good level in all aspects. They were also found to manage the operations in accordance with change management of the hotels. It is also consistent with a study by Chatichai Kongpetdit and $[7,8]$. "Change Management: Role of Leadership and Organizational Communication", which found that an organization needs to drive its various missions in order to survive, 
grow, and continue to operate with stability and sustainability to benefit the human resource management of the organization and all stakeholders. It is also to recognize operations under the conditions of organizational changes and the roles of organizational leadership and communication.

2. The "PROCESS" of change management of private companies in Bangkok under the context of Thailand Context 4.0 driven by innovation was overall at a high level with factors such as; executives have strategies for motivating and incentivizing subordinates in their work, executives are able to make timely decisions to modify plans and management to be in accordance with changes, and executives operate with flexibility in management. This is in accordance with the study [7]. "Change Management: Role of Leadership and Organizational Communication" and the study of [6]. "Organization change management for accommodating Chinese Travellers: A case study of 4 stars hotels, Tambon Chang Klan, Chiang Mai Province" which found that there was a designation of change management policy or strategy for organizational change in order to operate according to the needs of Chinese tourists and the current changing environment.

3.The "OUTPUT" of change management of private companies in Bangkok under the context of Thailand Context 4.0 driven by innovation was overall at a high level with factors such as; ability to perform tasks in entirety and without error, possibility of growth in the company, and ability to manage work in time. This is in line with a study of [9] "Leadership style and performance of employees" which stated that leadership is a role of executives [10] and also an important tool that can prominently bring strategies into operations for the efficiency of the organization and thus it can be considered a key factor or the heart of the organization.

\section{Suggestions}

Development of change management under the context of Thailand 4.0 driven by innovation nowadays is rapidly changing which affects people's lifestyle and business practices. Therefore, in the future there may be new changes that may affect the standard of business operation in various industries, especially businesses in technology and innovation which should be aware of the environment in an age which people prefer more convenience and comfort. The business sector must develop and adapt to keep pace with the changes and be open to new ideas in order to be able to have a comprehensive outlook without neglecting the needs of any part of the market.

\section{References}

1. J. Saensuk, Journal of the Association of Researchers 19(1), 34-46 (2014)

2. A. Arkhipov et al., E-Planning and Collaboration: Concepts, Methodologies, Tools, and Applications 2-3, 799-817 (2018)

3. M. Vinichenko et al., Espacios 40(19) (2019)

4. S. Banla, Transformational Leadership of School Administrators Affecting the Learning Organization of Schools Amphoe Mueang Pathumthani (Rajamangala University of Technology, Bangkok, 2011)

5. T. Sanpaudom, Self-development needs of staff at a beverage production company in Amata Nakhon Industrial Estate, Chonburi Province (Chonburi Burapha University, 2017). 
6. A. Cosentino et al., Organization change management for accommodating Chinese Travellers: A case study of 4 stars hotels, Tambon Chang Klan, Chiang Mai Province (Chiang Mai, Payap University, 2017)

7. C. Kongpetdit et al., Veridian E-journal 9(1), 895-919 (2016)

8. S. Chayanon et al., The EUrASEANs: Journal on Global Socio-Economic Dynamics 4(17), 16-29 (2019)

9. W. Siekbunrot, Leadership style and performance of employees (Pathum Thani, Western University, 2015)

10. M. Ihnatenko et al. International Journal of Economics and Business Administration, 7(2), 290-301 (2019) 